\title{
IMPLEMENTASI SISTEM CERDAS LEAST SQUARE DALAM MERAMALKAN PEMENUHAN KEBUTUHAN STOK LISTRIK DI KOTA LHOKSEUMAWE
}

\author{
Muhammad Sadli ${ }^{1}$, Safwandi ${ }^{2}$ \\ ${ }^{1,2}$ Jurusan Teknik Elektro Fakultas Teknik - Universitas Malikussaleh \\ E-mail: muhammad.sadli03@gmail.com
}

\begin{abstract}
PLN (Perusahaan Listrik Negara) is one of the BUMN (Badan Usaha Milik Negara) in charge of providing electricity supply needs with the best service quality for the community. The growth of electricity demand for residents of Lhokseumawe City by 2020 is expected to increase to 10\%. Based on these predictions, PLN must be able to forecast patterns from data needs lsitrik which has been then used to project the data that will come in order to give the best pelyanan for the community. Forecasting is one of the sciences in the field of intelligent systems that can predict longterm electrical demand in the city of Lhokseumawe. The least square forecasting model can be one of the components supporting the economic growth of Lhokseumawe City. Variables to be predicted in the fulfillment of electricity stocks are seen from household, industrial, commercial and public expenses. Furthermore, the need for electricity stock from each region will be seen from the installed capacity, power capable $(M W)$ and peak load. Then the least quare forecasting model will determine the equation of data trend based on the data needs of electricity that has been then used to project the data needs of electricity to come.

This research is expected to produce accurate forecasting value so that can be used as a reference for PLN party in taking policy. Proper forecasting can help PLN to save production cost due to mis-distribution. The specific target of this research is to know the quality of service PLN Lhokseumawe to the public so that the distribution of electricity is always stable. The long-term goal of implementing this smart forecasting system is to help improve the quality of PLN's services in meeting the long-term electricity needs of the people of Lhokseumawe.
\end{abstract}

Keywords: Electrical load, forecasting, Forecast Electricity Requirement, least square.

\section{INTISARI}

PLN (Perusahaan Listrik Negara) merupakan salah satu BUMN (Badan Usaha Milik Negara) yang bertugas menyediakan stok kebutuhan listrik dengan kualitas pelayanan terbaik bagi masyarakat. Pertumbuhan kebutuhan listrik bagi penduduk Kota Lhokseumawe pada tahun 2020 diperkirakan akan mengalami kenaikan sampai 10\%. Berdasarkan prediksi tersebut, PLN harus mampu meramalkan pola dari data kebutuhan lsitrik yang telah lalu kemudian digunakan untuk memproyeksikan data yang akan datang agar dapat meberikan pelyanan terbaik bagi masyarakat. Peramalan merupakan salah satu ilmu dalam bidang sistem cerdas yang dapat meramalkan kebutuhan stok listrik jangka panjang di Kota Lhokseumawe. Model peramalan least square dapat menjadi salah satu komponen yang mendukung pertumbuhan ekonomi Kota Lhokseumawe. Variable yang akan diramalkan dalam pemenuhan stok listrik dilihat dari beban rumah tangga, industri, komersial dan publik. Selanjutnya kebutuhan stok listrik dari masing-masing daerah akan dilihat dari kapasitas terpasang, daya mampu (MW) dan beban puncak. Kemudian model peramalan least quare akan menentukan persamaan trend data berdasarkan data kebutuhan listrik yang telah lalu kemudian digunakan untuk memproyeksikan data kebutuhan listrik yang akan datang.

Penelitian ini diharapkan dapat menghasilkan nilai peramalan yang tepat sehingga dapat dijadikan sebagai acuan bagi pihak PLN dalam mengambil kebijakan. Peramalan yang tepat dapat membantu pihak PLN menghemat biaya produksi akibat kesalahan pendistribusian. Target khusus dari penelitian ini adalah untuk mengetahui kualitas pelayanan pihak PLN Kota Lhokseumawe kepada masyarakat sehingga pendistribusian listrik selalu stabil. Tujuan jangka panjang dari implementasi sistem cerdas peramalan ini adalah untuk membantu meningkatkan kualitas pelayanan PLN dalam memenuhi kebutuhan listrik jangka panjang bagi masyarakat Kota Lhokseumawe.

Kata Kunci : Beban listrik, forecasting, least quare, Perkiran Kebutuhan Listrik

\section{PENDAHULUAN}

Energi listrik merupakan salah satu komponen utama dalam mendukung pertumbuhan suatu daerah. Persentase konsumsi listrik juga dapat menjadi ukuran peningkatan kualitas masyarakat dan pertumbuhan ekonomi. Di antaranya dalam bidang pendidikan, 
perindustrian, perumahan, perkantoran dan pendapatan suatu daerah. Perkiraan perkembangan beban listrik suatu wilayah merupakan yang sangat penting dalam perencanaan pemasangan kapasitas trafo. Peningkatan pemakai energi listrik suatu wilayah akan menuntun suatu upaya dan pemeliharaan kapasitas dari suatu gardu induk yang sesuai dalam upaya untuk pemenuhan energi listrik. Jika besarnya energi listrik yang tidak sesuai dengan kebutuhan masyarakat kota Lhokseumawe.

Kebutuhan stok untuk distribusi listrik pada konsumen harus optimal sesuai dengan besar kebutuhan dari masyarakat dan industri yang berada di daerahnya. Masalah akan timbul apabila daya yang dikirim dari suatu pembangkit listrik jauh lebih besar daripada permintaan daya pada beban, maka akan terjadi pemborosan energi pada perusahaan listrik. Oleh karena itu, diperlukan strategi dan metode untuk peramalan dalam penyesuaian antara pemenuhan stok kebutuhan daya listrik dan permintaan daya. Agar tercapai penyesuaian antara pembangkitan dan permintaan daya, maka pihak penyedia listrik harus mengetahui beban atau permintaan daya listrik untuk beberapa waktu ke depan dengan melakukan perkiraan beban listrik.

Pentingnya menyelesaikan ketersediaan listrik kini telah menjadi bahasan utama di masyarakat seiring dengan meningkatnya pertumbuhan sosial ekonomi masyarakat itu sendiri. Untuk menghindari terjadinya krisis energi listrik, maka diperlukan suatu model peramalan sebagai langkah awal dalam usaha pengembangan sistem ketenaga listrikan dengan melakukan suatu prakiraan mengenai besarnya kebutuhan listrik pada tahun-tahun mendatang. Sehingga dapat diketahui mengenai besar tambahan pasokan energi listrik yang diperlukan, dan kapan waktu yang tepat untuk penambahan jumlah pasokan energi listrik.

Permasalahan peramalan dalam analisis permintaan terutama permintaan kebutuhan stok listrik dengan mengukur permintaan sekarang dan meramalkan kondisi pada masa yang akan datang. Mengukur permintaan sekarang berarti menganalisa kondisi sekarang dan sebelumnya sebagai sumber inhalamanasi untuk memprediksi keadaan yang akan datang dengan asumsi keadaan masa lalu akan berulang lagi di masa depan. Model least quare adalah suatu metode yang paling luas digunakan untuk menentukan persamaan trend data. Proses least square mengukur permintaan sekarang untuk menganalisa kondisi sekarang dan sebelumnya sebagai sumber inhalamanasi untuk memprediksi keadaan yang akan datang dengan asumsi keadaan masa lalu akan berulang lagi di masa depan.

\section{DASAR TEORI}

\section{A. Sistem Tenaga Listrik [1]}

Sistem tenaga listrik merupakan suatu sistem yang kompleks yang memiliki 3 komponen yang tidak bisa dipisahkan satu dengan yang lain. Ketiga komponen tersebut adalah :

1. Sistem Pembangkitan, yaitu suatu sistem yang memproduksi tenaga listrik pada pusat pembangkit dengan berbagai macam jenis pembangkit tenaga listrik.

2. Sistem Transmisi, yaitu suatu sistem yang menyalurkan tenaga listrik dari sumber pembangkitan ke suatu sistem distribusi melalui saluran transmisi. Transmisi tenaga dengan tegangan tinggi maupun ekstra tinggi pada saluran transmisi di ubah pada gardu induk menjadi tegangan menengah distribusi primer yang selanjutnya diturunkan menjadi tegangan untuk konsumen.

3. Sistem Distribusi, yaitu suatu sistem yang berfungsi untuk mendistribusikan tenaga listrik ke konsumen yang berupa pabrik, perumahan, bisnis, perkantoran pemerintah, dan sebagainya.

\section{B. Sistem Distribusi Tenaga Listrik}

Sistem distribusi tenaga listrik suatu sistem tenaga listrik dapat dibagi dalam tiga komponen utama atau tiga fungsi yaitu : sistem pembangkitan, sistem transmisi (penyaluran), dan sistem distribusi. Sistem distribusi merupakan bagian dari sistem tenaga listrik yang berada paling dekat dengan sisi beban/pelanggan [5].

Suatu sistem tenaga listrik dapat dibagi dalam tiga komponen utama atau tiga fungsi yaitu : sistem pembangkitan, sistem transmisi (penyaluran), dan sistem distribusi. Sistem distribusi merupakan bagian dari sistem tenaga 
listrik yang berada paling dekat dengan sisi beban/pelanggan. Dimana sistem distribusi bertugas menyalurkan dan mendistribusikan tenaga listrik dari pusat suplai yang dalam hal ini dapat berupa gardu induk atau pusat pembangkit ke pusat-pusat/kelompok beban (gardu distribusi) dan pelanggan melalui jaringan primer dan jaringan sekunder. Tenaga listrik yang didistribusikan ke pelanggan (konsumen) digunakan sebagai sumber daya untuk bermacam-macam peralatan yang membutuhkan tenaga listrik sebagai sumber energinya. Peralatan tersebut umumnya bisa berupa lampu (penerangan), beban daya (untuk motor listrik), pemanas, dan sumber daya peralatan elektronik.

Sistem Distribusi Tenaga Listrik” Peramalan Beban dan Kebutuhan Energi Listrik, menjelaskan bahwa peramalan pada dasarnya merupakan suatu dugaan atau prakiraan mengenani terjadinya suatu kejadian atau peristiwa dimasa yang akan datang. Dalam kegiatan perencanaan peramalan merupakan kegiatan mula dari proses tersebut. Ramalan di bidang tenaga elektrik pada dasarnya merupakan ramalan kebutuhan energi elektrik (Watt-jam) dan ramalan beban tenaga elektrik (Watt). Keduanya sering disebut dengan istilah Demand and Load Forecasting. Hasil peramalan ini dipergunakan untuk membuat rencana pemenuham kebutuhan maupun pengembangan penyediaan tenaga elektrik setiap saat secara cukup dan baik serta terus menerus. Penentuan metode dan pembuatan model [3].

\section{Peramalan Kebutuhan Listrik}

Peramalan merupakan suatu teknik untuk memperkirakan atau memprediksikan suatu nilai pada masa yang akan datang dengan memperhatikan data atau inhalamanasi masa lalu atau saat ini baik secara matematik atau statistik. Sedangkan ramalan adalah suatu situasi atau kondisi yang diperkirakan akan terjadi pada masa yang akan datang. Metode ini sangat membantu dalam mengambil keputusan yang tepat. Baik tidaknya suatu peramalan yang disusun ditentukan baik tidaknya inhalamanasi yang digunakan. Peramalan kuantitatif dapat digunakan bila terdapat 3 (tiga) kondisi, yaitu :

1. Ada inhalamanasi tentang masa lalu

2. Inhalamanasi tersebut dapat dikuantitatifkan dalam bentuk kata.
3. Inhalamanasi tersebut dapat diasumsikan bahwa beberapa aspek pola masa akan yang akan datang untuk efektivitas dan efisiensi dari sistem peramalan.

Peramalan (forecasting) merupakan alat bantu yang penting dalam perencanaan yang efektif dan efisien khususnya dalam bidang kebutuhan stok obat. Peramalan dilakukan adalah verifikasi peramalan sedemikian rupa sehingga mencerminkan data masa lalu dan sistem penyebab yang mendasari permintaan tersebut. Sepanjang representasi peramalan tersebut dapat dipercaya, hasil peramalan dapat terus digunakan Peramalan (forecasting) merupakan alat bantu yang penting dalam suatu pembuatan perencanaan bagi setiap organisasi bisnis dan untuk setiap pengambilan keputusan manajemen yang sangat signifikan [9].

Peramalan Energi listrik memiliki peranan yang sangat penting dalam kehidupan manusia, energi listrik banyak digunakan di berbagai sektor, baik sektor industri, rumah tanggga, usaha komersial, maupun sektor umum lainnya. Sejalan dengan perkembangan zaman dan kemajuan ilmu dan teknologi, kebutuhan akan ketersediaan energi listrik kian meningkat. Energi listrik tidak dapat disimpan dalam skala besar, sehingga energi ini harus disediakan pada saat dibutuhkan. peramalan beban listrik untuk memberikan inhalamanasi bagi penyedia listrik agar dapat memperkirakan besarnya permintaan sehingga dalam penyediaannya tidak terjadi pemborosan beban listrik yang dapat mengakibatkan kerugian [7].

Model peramalan yang dikembangkan untuk peramalan beban listrik hanya pada satu level pemodelan secara simultan. Pada tahun 2008, Soares dan Medeiros melakukan penelitian untuk peramalan beban listrik jangka pendek pada model dua level dengan melibatkan beberapa variabel eksternal, seperti tipe hari dan efek hari khusus untuk meramalkan beban listrik per-jam di Brazil. dua level dalam model, yaitu level pertama berdasarkan variabel dummy, dan tren linier yang diestimasi untuk menggambarkan adanya tren jangka panjang, pola musiman tahunan, pengaruh hari dalam seminggu, dan pengaruh dari hari-hari khusus lainnya. Sedangkan komponen kedua merupakan model linier yang mengikuti pola Autoregressive atau $\operatorname{AR}(p)$ [13]. 


\section{Metode Least Square}

Metode Least Square adalah suatu metode yang paling luas digunakan untuk menentukan persamaan trend data. Metode kuadrat terkecil yang dibagi dalam dua kasus, yaitu kasus data genap dan kasus data ganjil. Metode Least Square (kuadrat terkecil) paling sering digunakan untuk meramalkan Y, karena perhitungannya lebih teliti.

Garis least square ini mempunyai sifat-sifat:

1. Penjumlahan seluruh deviasi vertikal titiktitk data terhadap garis dalah nol.

2. Penjumlahan seluruh kuadrat deviasi vertikal data historis dari garis adalah minimum.

3. Garis melalui rata-rata $\mathrm{X}$ dan $\mathrm{Y}$.

Metode least square menggunakan caracara perhitungan statistika dan matematika tertentu untuk mengetahui fungsi garis lurus sebagai pengganti garis patah-patah yang dibentuk oleh data historis perusahaan [6].

Dengan demikian pengaruh unsur subyektif dapat dihindarkan. Persamaan trend dengan metode moment adalah sebagai berikut:

$$
\boldsymbol{Y}_{\boldsymbol{n}}=\boldsymbol{a}+(\boldsymbol{b} . \boldsymbol{X})
$$

\section{keterangan:}

$\mathrm{Y}_{\mathrm{n}}$ : Peramalan yang akan datang (peramalan)

a : bilangan konstant

$\mathrm{b}$ : slope atau koefisien kecondongan garis trend

$\mathrm{X}$ : jangka waktu atau selisih tahun $(\mathrm{x}=0,1,2$,

$$
3, \ldots, n)
$$

Sedangkan untuk menghitung nilai $a$ dan $b$ digunakan rumus sebagai berikut:

$$
\begin{aligned}
b & =\frac{\sum X Y}{\sum X^{2}} \\
a & =\frac{\sum Y}{n}
\end{aligned}
$$

\section{keterangan:}

$\sum X Y \quad$ : Jumlah kumulatif waktu dikalikan data historis

$\sum X^{2} \quad$ : jumlah rata-rata jangka waktu di kuadratkan

$\sum Y \quad$ : Jumlah rata-rata pendistribusian air

$\mathrm{n} \quad$ : banyaknya periode waktu (tahun)

Bila ada sejumlah periode waktu ganjil, titik tengah periode waktu ditentukan sebagai $X=0$, sehingga jumlah plus dan minus akan sama dengan nol.
Pengamatan pasut dilakukan untuk menentukan nilai komponen pasut yang nantinya dapat digunakan untuk keperluan kerekayasaan dan pemetaaan. Metode least squares dapat digunakan untuk menentukan komponenkomponen pasut selain metode Admiralty. Metode penentuan komponen pasut dan prediksinya yang umum menggunakan beberapa metode, yaitu metode Admiralty, metode semi grafik, metode least squares dan lainnya. Perhitungan menggunakan metode least squares menghasilkan nilai komponen amplitude yang mendekati nilai komponen hasil perhitungan metode Admiralty tetapi berbeda pada nilai fase. Metode least squares memberikan akurasi yang cukup baik pada hasil prediksi dan dengan komponen yang lebih banyak.

\section{METODE PENELITIAN}

\section{A. Tahapan Penelitian}

Penelitian ini dibagi dalam enam tahapan, yaitu identifikasi masalah, analisa kebutuhan sistem, implementasi dan sistem pengembangan, studi kasus dan uji coba sistem model least square, evaluasi dan pembenahan, pengambilan kesimpulan dan saran.

\section{B. Model yang Digunakan}

Model peramalan sistem cerdas menggunakan metode least square untuk memperoleh hasil dengan berpedoman pada proses least square.

\section{Rancangan Penelitian}

Langkah-langkah dalam penelitian implementasi sistem cerdas dalam meramalkan pemenuhan kebutuhan stok listrik untuk meningkatkan kualitas kepada masyarakat di kota Lhokseumawe adalah sebagai berikut:

1. Mengumpulkan data kebutuhan stok listrik, beban listrik, dari masing-masing daerah di Lhokseumawe dijadikan sebagai data pendukung, selanjutnya data tersebut dijadikan total keseluruhan dalam jumlah penduduk, jumlah rumah tangga, jumlah pelanggan listrik, daya terpasang dan konsumsi energi listrik.

2. Melakukan pemisahan data sesuai kebutuhan stok listrik dan kepuasan layanan masyarakat yang diperoleh dari PT PLN Lhokseumawe dan masyarakat dari 
masing-masing daerah yang akan dijadikan variable peramalan.

3. Memasukkan data-data keseluruhan jumlah yang telah di analisis berupa jumlah penduduk, jumlah rumah tangga, jumlah pelanggan listrik, PDRB, daya terpasang dan konsumsi energi listrik yang akan dimasukkan kedalam sistem database.

\section{Teknik Pengumpulan Data}

Dalam penelitian ini data yang diberikan diantaranya data stok kebutuhan listrik dari masing-masing daerah di kota lhokseumawe. Pengumpulan data yang diperlukan sebagai dasar dalam melakukan forecasting dalam penelitian ini dari tahun 2010 sampai tahun 2015. Pengumpulan data kualitas layanan masyarakat dilakukan menanyakan langsung kepada masyarkat pada tiap-tiap daerah dan memberikan nilai sesuai dengan variabel yang telah ditentukan.

\section{E. Analisa Data}

Dalam penelitian ini data yang digunakan diperoleh dari orang-orang yang bertanggung jawab memberikan data di PT. PLN Kota Lhokseumawe berupa data masing-masing dari pelanggan yang berada di daerah kota. Data yang diberikan diantaranya data stok kebutuhan listrik dari semua pelanggan yang digunakan. Selanjutnya melakukan pemisahan data sesuai kebutuhan peneliti yang diperoleh di PT. PLN Kota Lhokseumawe.

\section{F. Perancangan Analisis Database, User} Interface dan Pengujian

Pada tahap ini penulis menyusun sebuah database untuk menyimpan data yang diinput. Adapun rancangan database yang digunakan adalah database berbasis MySQL. Pengkodean untuk mengimplementasikan perancangan aplikasi peramalan kedalam bahasa pemograman. Tahapan akhir adalah melakukan debugging atau testing program. Pengujian dilakukan dengan mencoba secara detail aplikasi yang ditampilkan oleh interface.

\section{HASIL DAN PEMBAHASAN}

\section{A. Analisa Sistem}

Pertumbuhan kebutuhan listrik bagi penduduk Kota Lhokseumawe pada tahun 2020 diperkirakan akan mengalami kenaikan sampai
$10 \%$. Berdasarkan prediksi tersebut, PLN harus mampu meramalkan pola dari data kebutuhan lsitrik yang telah lalu kemudian digunakan untuk memproyeksikan data yang akan datang agar dapat meberikan pelayanan terbaik bagi masyarakat

Model peramalan least square dapat menjadi salah satu komponen yang mendukung pertumbuhan ekonomi Kota Lhokseumawe. Variable yang akan diramalkan dalam pemenuhan stok listrik dilihat dari beban rumah tangga, industri, komersial dan publik. Selanjutnya kebutuhan stok listrik dari masingmasing daerah akan dilihat dari kapasitas terpasang, daya mampu (MW) dan beban puncak. Kemudian model peramalan least quare akan menentukan persamaan trend data berdasarkan data kebutuhan listrik yang telah lalu kemudian digunakan untuk memproyeksikan data kebutuhan listrik yang akan datang.

\section{B. Perancangan Sistem}

Perancangan Sistem (Desain Sistem) merupakan gambaran atau sketsa dari alur proses sistem pengolahan data. Rancangan suatu sistem dapat menggunakan Diagram Arus Data (DAD) atau Data Flow Diagram (DFD).

\section{Diagram konteks}

Diagram aliran data hanya memuat satu proses dan menunjukkan sistem secara keseluruhan. Adapun bentuk diagram konteks dari Implementasi Sistem Cerdas Least Square dalam Meramalkan Pemenuhan Kebutuhan Stok Listrik.

\section{Perancangan Basis Data}

Pemodelan data merupakan proses pendesainan file-file database yang berfungsi sebagai sumber data. Adapun bentuk pemodelan data tersebut adalah sebagai berikut :

1. Tabel Admin

Tabel 1 ini berfungsi menyimpan data Admin. Tabel ini terdiri dari tiga field, yaitu: field Id_user sebagai kunci primarykey, field username, dan field password.

Tabel 1. Tabel Admin

\begin{tabular}{|c|c|c|c|}
\hline Nama & Type & Ukuran & Keterangan \\
\hline *Id_user & Varchar & 15 & Primarykey \\
\hline Username & Varchar & 15 & \\
\hline Password & Varchar & 15 & \\
\hline
\end{tabular}


2. Tabel Pelanggan

Tabel ini berfungsi untuk menyimpan data Pelanggan(responder) yang mengikuti kuisioner. Tabel ini terdiri dari lima field, yaitu field id_Pelanggan, field nama, field jenis_kel, field usia dan field pend._akhir.

Tabel 2. Tabel Pelanggan

\begin{tabular}{|l|c|c|c|}
\hline \multicolumn{1}{|c|}{ Nama } & Type & Ukuran & Keterangan \\
\hline *Id_Pelanggan & Varchar & 10 & Primarykey \\
\hline Nama & Varchar & 30 & \\
\hline Jenis_kel & Varchar & 15 & \\
\hline Usia & Varchar & 15 & \\
\hline Pend_akhir & Varchar & 15 & \\
\hline
\end{tabular}

3. Tabel Pertanyaan

Tabel ini berfungsi untuk menyimpan data pertanyaan kuisioner yang di_input oleh admin. Tabel ini terdiri dari lima field, yaitu field id_pertanyaan, field pertanyaan, field $\mathrm{a}$, field $\mathrm{b}$ dan field $\mathrm{c}$.

Tabel 3. Tabel Pertanyaan

\begin{tabular}{|l|c|c|l|}
\hline \multicolumn{1}{|c|}{ Nama } & Type & Ukuran & Keterangan \\
\hline *Id_pertanyaan & Varchar & 10 & Primarykey \\
\hline Pertanyaan & Text & 0 & \\
\hline a & Varchar & 25 & Jawaban a \\
\hline b & Varchar & 25 & Jawaban b \\
\hline
\end{tabular}

4. Tabel Jawaban

Tabel ini berfungsi untuk menyimpan data jawaban dari setiap Pelanggan(responder) yang mengikuti kuisioner. Tabel ini terdiri dari enam field, yaitu field id jawab, field id_Pelanggan, field id pertanyaan, field pertanyaan, field jawaban, dan field nilai.

Tabel 4. Tabel Jawaban

\begin{tabular}{|l|c|c|c|}
\hline \multicolumn{1}{|c|}{ Nama } & Type & Ukuran & Keterangan \\
\hline *Id_jawab & Varchar & 10 & Primarykey \\
\hline Id_Pelanggan & Varchar & 10 & \\
\hline Id_pertanyaan & Varchar & 10 & \\
\hline Pertanyaan & Text & 0 & \\
\hline jawaban & Varchar & 25 & \\
\hline Nilai & Int & 11 & \\
\hline
\end{tabular}

5. Tabel Analisa

Tabel ini berfungsi untuk menyimpan data hasil dari analisa tingkat kualitas pelayanan berdasarkan data kuisioner. Tabel ini terdiri dari enam field, yaitu field id jawab, field id_Pelanggan, field id_pertanyaan, field pertanyaan, field jawaban, dan field nilai.
Tabel 5. Tabel Analisa

\begin{tabular}{|l|c|c|l|}
\hline \multicolumn{1}{|c|}{ Nama } & Type & Ukuran & Keterangan \\
\hline *Id_analisa & Varchar & 10 & Primarykey \\
\hline Id_Pelanggan & Varchar & 10 & \\
\hline Nama & Varchar & 10 & \\
\hline Jenis_Kel & Varchar & 15 & \\
\hline Nilai & Float & 0 & \\
\hline Tingkat & Varchar & 20 & \\
\hline
\end{tabular}

6. Tabel Tingkat

Tabel ini berfungsi untuk menyimpan data berupa parameter nilai untuk menentukan penilaian terhadap tingkat kualitas pelayanan. Tabel ini terdiri dari empat field, yaitu field id tingkat, field tingkat, field nilai_max dan field nilai_min.

Tabel 6. Tabel Tingkat

\begin{tabular}{|l|c|c|l|}
\hline \multicolumn{1}{|c|}{ Nama } & Type & Ukuran & Keterangan \\
\hline *Id_tingkat & Varchar & 10 & Primarykey \\
\hline tingkat & Varchar & 20 & \\
\hline Nilai_max & Int & 11 & \\
\hline Nilai_min & Int & 11 & \\
\hline
\end{tabular}

E. Perhitungan Menggunakan Metode Least Square

1. Data Pemakaian Beban Listrik Rumah Tangga

Data pemakaian beban listrik rumah tangga pada tabel data aktual selama 36 bulan dari tahun 2013 sampai 2015 seperti yang terlihat pada Tabel 7.

Tabel 7. Tabel Data Aktual Pemakaian Beban Listrik Rumah Tangga

\begin{tabular}{|c|c|c|c|c|c|}
\hline Bulan & Tahun & $\begin{array}{c}\text { Jumlah } \\
\text { Beban } \\
\text { Listrik } \\
\text { (Y) }\end{array}$ & Bulan & Tahun & $\begin{array}{c}\text { Jumlah } \\
\text { Beban } \\
\text { Listrik } \\
\text { (Y) }\end{array}$ \\
\hline Januari & 2013 & 276 & Mei & 2014 & 168 \\
\hline Februari & 2013 & 238 & Juni & 2014 & 257 \\
\hline Maret & 2013 & 185 & Juli & 2014 & 185 \\
\hline April & 2013 & 179 & Agustus & 2014 & 284 \\
\hline Mei & 2013 & 276 & September & 2014 & 306 \\
\hline Juni & 2013 & 269 & Oktober & 2014 & 314 \\
\hline Juli & 2013 & 303 & November & 2014 & 155 \\
\hline Agustus & 2013 & 329 & Desemb & 2014 & 221 \\
\hline September & 2013 & 204 & Januari & 2015 & 188 \\
\hline Oktober & 2013 & 285 & Februari & 2015 & 203 \\
\hline November & 2013 & 153 & Maret & 2015 & 324 \\
\hline Desember & 2013 & 264 & April & 2015 & 337 \\
\hline Januari & 2014 & 288 & September & 2015 & 310 \\
\hline Februari & 2014 & 296 & Oktober & 2015 & 277 \\
\hline Maret & 2014 & 183 & November & 2015 & 222 \\
\hline April & 2014 & 294 & Desember & 2015 & 192 \\
\hline & Keseluruhan $\sum$ Y= & 8780 \\
\hline
\end{tabular}


Perhitungan peramalan penduduk menggunakan metode Least Square sebagai berikut :

1. Tentukan Nilai a

$$
\boldsymbol{a}=\frac{\sum Y}{\boldsymbol{n}}=\frac{8780}{36}=\mathbf{2 4 3 . 8 8}
$$

2. Tentukan Nilai b

$$
\boldsymbol{b}=\frac{\sum \boldsymbol{X} \boldsymbol{Y}}{\sum \boldsymbol{X}^{\mathbf{2}}}=\frac{2854}{15540}=0.18365
$$

3. Perhitungan Penduduk Yang Lalu Menggunakan Metode Least Square

$$
\begin{aligned}
& Y_{1}=a+(b . X) \\
& =243.88 \\
& +(0.18365 .(35)) \\
& =250.317 \\
& Y_{2}=a+(b . X) \\
& =243.88 \\
& +(\text { 0.18365. ( 33) }) \\
& =249.95 \\
& Y_{3}=a+(b . X) \\
& =243.88 \\
& +(\text { 0.18365. ( 31) }) \\
& =249.582 \\
& Y_{4}=a+(b . X) \\
& =243.881 \\
& +(\text { 0.18365. ( 29)) } \\
& =249.215 \\
& Y_{5}=a+(b . X) \\
& \begin{array}{l}
=243.881 \\
+(0.18365 .( \\
=248.848
\end{array}
\end{aligned}
$$

4. Perhitungan pemakaian beban listrik rumah tangga selama lima bulan selanjutnya pada tahun 2018 menggunakan metode Least Square

$$
\begin{aligned}
\boldsymbol{Y}_{\mathbf{3 6}}=\boldsymbol{a}+(\boldsymbol{b} . \boldsymbol{X}) & \\
& =243.88 \\
& +(0.18365 .(36)) \\
& =236.73 \\
\boldsymbol{Y}_{\mathbf{3 7}}=\boldsymbol{a}+(\boldsymbol{b} . \boldsymbol{X}) & \\
& =243.88 \\
& +(0.18365 .(37)) \\
& =236.36 \\
\boldsymbol{Y}_{\mathbf{3 8}}=\boldsymbol{a}+(\boldsymbol{b} . & \boldsymbol{X}) \\
& =243.88 \\
& +(0.18365 .(38)) \\
& =235.99
\end{aligned}
$$

$$
\begin{aligned}
\boldsymbol{Y}_{\mathbf{3 9}}=\boldsymbol{a}+(\boldsymbol{b} . \boldsymbol{X}) & \\
& =243.88 \\
& +(0.18365 .(39)) \\
& =235.62 \\
\boldsymbol{Y}_{\mathbf{4 0}}=\boldsymbol{a}+(\boldsymbol{b} . \boldsymbol{X}) & \\
& =243.88 \\
& +(0.18365 .(40)) \\
& =235.26
\end{aligned}
$$

Tabel 8. Prediksi Ramalan Beban Listrik Selama 5 Bulan ke Depan

\begin{tabular}{|c|c|c|}
\hline Bulan & Tahun & $\begin{array}{c}\text { Jumlah Beban } \\
\text { Listrik (KwH) }\end{array}$ \\
\hline Januari & 2018 & 236.73 \\
\hline Februari & 2018 & 236.36 \\
\hline Maret & 2018 & 235.99 \\
\hline April & 2018 & 235.62 \\
\hline Mei & 2018 & 235.26 \\
\hline \multicolumn{2}{|l}{}
\end{tabular}

F. Program Aplikasi

1. Halaman Login

Halaman login ini sebagai tampilan menu awal program yang berisi pendaftar, login dan keluar. Adapun tampilan halaman login dapat dilihat pada Gambar 1.

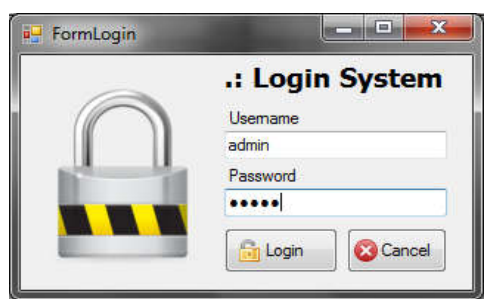

Gambar 1. Halaman Login System

2. Halaman Input Data Beban Listrik

Halaman menu input beban listrik meliputi ID, Tahun, Bulan, Jenis beban listrik, jumlah terlihat pada Gambar 2.

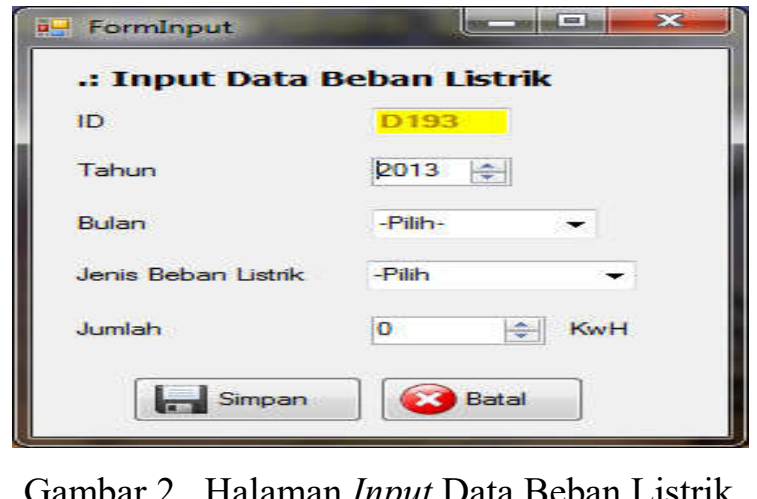

Gambar 2. Halaman Input Data Beban Listrik 
3. Halaman Lihat Data Beban Listrik

Halaman ini digunakan untuk melihat data beban listrik yang dapat dilihat pada Gambar 3 .

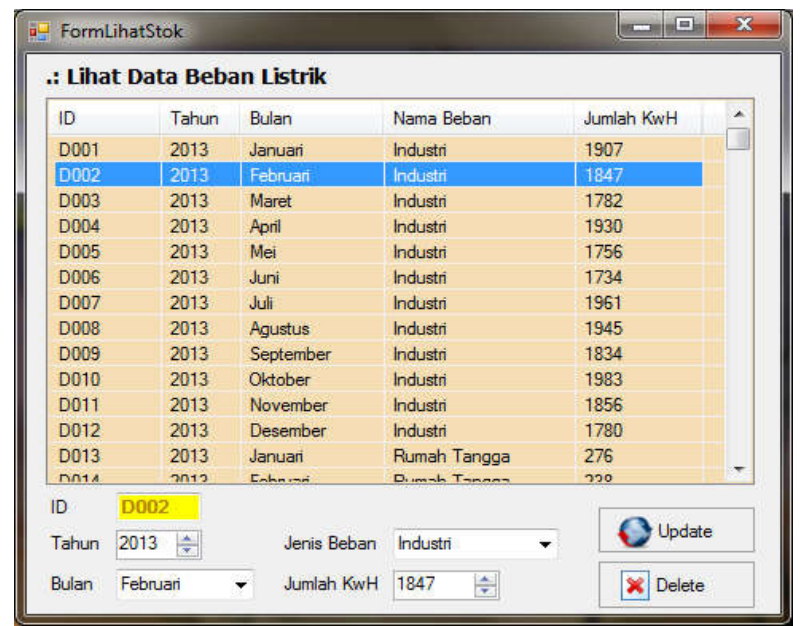

Gambar 3. Halaman Data Beban Listrik

\section{Halaman Pilih Data Jenis Beban Listrik}

Halaman ini digunakan untuk peramalan menggunakan metode least square yang dapat dilihat pada Gambar 4.

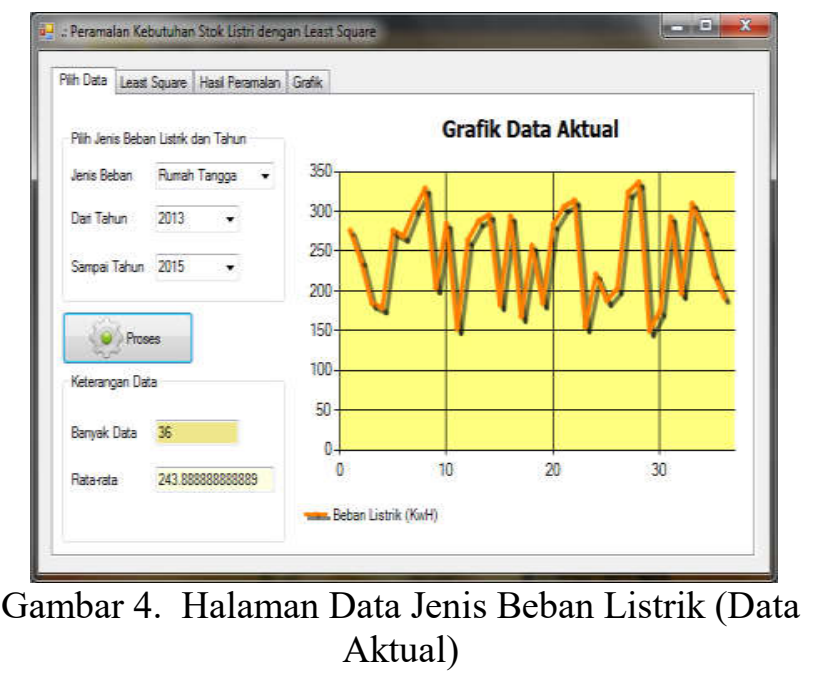

\section{KESIMPULAN}

Dari hasil dan pembahasan Implementasi Sistem Cerdas Least Square Dalam Meramalkan Pemenuhan Kebutuhan Stok Listrik Kepada Masyarakat Di Kota Lhokseumawe dapat diambil kesimpulan sebagai berikut:

1. Dapat memudahkan PT. PLN dengan metode peramalan metode least square dapat memprediksi kebutuhan energi listrik dari tiap sektor yaitu diantaranya sektor rumah tangga, sektor komersial, sektor publik, dan sektor industri.
2. Memudahkan pihak PT. PLN dalam meramalkan pemenuhan kebutuhan stok listrik di masing-masing daerah yang dilihat dari permintaan sekarang dari sektor rumah tangga, sektor komersial, sektor publik, dan sektor industri dan memprediksikan permintaan kebutuhan stok listrik untuk kedepannya.

\section{DAFTAR PUSTAKA}

[1] Dewi, A. Y. dan Febrizal, Y. (2012). Prediksi Kebutuhan Energi Listrik 2012. Jurnal Teknik Elektro ITP, Volume. 1, No. 1. Fakultas Teknologi Industri, Institut Teknologi Padang.

[2] Mohammad, A. (2009). Pengaruh Kualitas Pelayanan Terhadap Kepuasan Pelanggan (Studi Pada Perusahaan Penerbangan PT. Garuda Di Kota Semarang). Jurnal Ekonomi dan Bisnis. Vol. 10. No.2. Juli. Hal. 171 186. Unisulla Semarang.

[3] Suswanto, D. (2009). Sistem Distribusi Tenaga Listrik Edisi Pertama. Buku Ajar, Universitas Negeri Padang, Padang.

[4] Marsudi, D. (2010). Operasi sistem Tenaga Listrik. Graha Ilmu, Yogyakarta.

[5] Firdaus, I. (2010). Analisa Prakiraan Beban Puncak Dengan Menggunakan Metode Dekomposisi Pada Gardu Induk Banda Aceh. Tugas Akhir Fakultas Teknik Unsyiah, Banda Aceh.

[6] Ginting, R. (2007). Sistem Produksi. Graha Ilmu, Yogyakarta.

[7] Purnamasari, I. dan Suhartono. (2012). Metode tlsar berbasis regresi time series dan moving average untuk peramalan beban listrik jangka pendek. Prosiding Seminar Nasional Penelitian, Pendidikan dan Penerapan MIPA, Fakultas MIPA, Universitas Negeri Yogyakarta, Yogyakarta.

[8] Supranto, J. (2001). Statistik Teori dan Aplikasi Jilid 2 Ed.6. Penerbit Erlangga, Jakarta. 
[9] Rambe, M. I. F. (2014). Perancangan Aplikasi Peramalan Persediaan Obatobatan Menggunakan Metode Least Square (Studi Kasus : Apotik Mutiara Hati). Pelita Informatika Budi Darma, Volume : VI, Nomor: 1, Maret 2014 ISSN : 2301-9425.

[10] Nugroho, A. (2011). Perancangan dan Implementasi Sistem Basis Data. Penerbit Andi, Yogyakarta.

[11] Syahrizal, M. dkk. (2008). Peramalan Kebutuhan Beban Sistem Tenaga Listrik Menggunakan Algoritma Genetik. UIN Sultan Syarif Kasim, Riau.

[12] Simarta, J. dan Paryudi. I. (2010). Basis Data. Penerbit Andi, Yogyakarta.

[13] Soares, L. J., and Medeiros, M. C. (2008). Modeling and Forecasting short-term electricity load: A comparison of methods with an application to Brazilian data. International Journal of Forecasting, 24, 630-644.

[14] Sonya, M. (2010). Analisis Pengaruh Kualitas Pelayanan Terhadap Kepuasan Pelanggan Dalam Pembayaran Rekening Listrik (Studi Pada Unit Pelayanan Pelanggan Semarang Barat). Universitas Diponegoro.

[15] Utama, N. P. S. (2007). Prakiraan Kebutuhan Tenaga Listrik Propinsi Bali Sampai Tahun 2018. Teknik Elektro, Vol.6 No.1.

[16] Varga, (2010). Medium Term Electric Load forecasting Using Artificial Neural Networks. Electric Power Engineering. 2010 PowerTech Budapest 99. International Conference on. IEEE Conference Publications. hlm. 37, DOI: 10.1109/PTC.1999.826468, Teknik Analisis Regresi dan Korelasi.

[17] Wei, W., (2008). Time Analysis Univariate and Multivariate Methods. Addison Wesley Publishing Company, Inc. America. 